\title{
Feasibility Study on the Application of EAP in General English Teaching of Fujian-Taiwan Cooperation of Universities
}

\author{
Zhen Chen ${ }^{1, \text { a }}$ \\ ${ }^{1}$ Ocean Department of Fuzhou University, Fuzhou, Fujian, China, 350116 \\ ${ }^{\mathrm{a}}$ email
}

Keywords: EAP, General English, Fujian-Taiwan Cooperation of Universities

\begin{abstract}
EAP (English for Academic Purposes) is designed to help learners to develop their professional knowledge in English. It was applied in the general English teaching of Fujian-Taiwan cooperation of universities and has achieved good results. This paper analyses the concept and characteristics of EAP and establishes a new college general English teaching mode of cooperation between Fujian and Taiwan in order to provide references for the related researchers.
\end{abstract}

\section{Concept and Features of EAP}

The formation and development of EAP is closely related to the development of linguistics, especially the development of applied linguistics in the UK. Its formation and development can be divided into two stages. The language research of EAP began in twentieth Century, five, 60s. The academic research of this period advocates the objectivity and the scientific experiment method. At that time, the general view is that science and academic language in rhetoric is simple, and its language is transparent, and can be used to transport knowledge, hypothesis, methods and experimental results. In 1964, Mcintosh, Halliday and Strevens published a book named The Linguistic Sciences and Language Teaching, which is of great significance to the development of linguistics and EAP. This book has made a lot of new ideas on language and language teaching. Theoretical linguistics regards language as an abstract system. Applied linguistics regards language as a tool of communication, and the use of language varies with the context. This view of language is that if the language learners use language as an abstract system to grasp, they cannot be in the specific context of the use of language to communicate. Therefore, language teaching should be based on the specific communicative situation. In this book, the authors put forward the register analysis the notion to analyze the vocabulary and syntax.

Theoretically, EAP is applied to the transition course from public English teaching to bilingual teaching in universities, which is determined by the relationship between EAP, public English and bilingual teaching. Public English is a basic language skill, which is the core of non-English majors. It focuses on cultivating students' listening, speaking, reading, writing, translation and other basic language skills. Bilingual teaching is a tool for learning English as a tool to learn the professional knowledge, access to professional knowledge, therefore, the bilingual teaching in the teaching of professional courses. Therefore, the teaching purpose of EAP is very clear, one is to meet the needs of the learners to learn the special needs directly, and the two is to conform to the objective requirements of the development of modern society for international and compound talents. Professional English has its own vocabulary, syntax and discourse characteristics. It has a unique learning system. It is difficult for the students to adapt to the environment of bilingual teaching only 
through the study of the basic course of public English. This is exactly the point of intervention in EAP and a reform direction of English.

\section{Talent Training Mode of Fujian-Taiwan Cooperation of Universities in Fuzhou University}

From 2012, Fuzhou University and some Taiwan Universities cooperated on the personnel training projects and implemented the $3+1$ joint personnel training mode. The teaching materials of students coming to Taiwan learning are full English textbooks, including academic exchange programs. EAP stratified teaching model as a set of English language skills, professional knowledge, cultural background, application ability of learning is one of the open, multi-level English teaching system for training talents to explore an effective teaching approach, the model according to the different stages of the University for the different needs of learning, namely the creation of some general academic English, academic English courses and genre ability application course. The education cooperation between Fujian and Taiwan aimed to focus on the cultivation of marine industry in urgent need of marine engineering and marine science senior applied talents. In teacher and professional person in charge of carefully selected and recommended on the basis, the college purchased a lot of research at the forefront of English original books reference room built, for EAP teaching materials selection and prepared to provide hardware support. The teaching materials enable students to adapt to the real academic environment or occupational environment in the effective use of English professional learning goals.

Although freshmen have a certain foundation for the English language, due to lack of language knowledge and language skills, students will encounter difficulties when reading professional textbooks. The start of general academic English courses, such as English debating skills, grammatical skills, academic reading skills, note taking skills, listening skills, shorthand skills courses, guide the students to find out language learning internal and relationship skills and self-understanding process rules, using scaffolding learning strategies, to improve the independent learning management skills, in order to enter the study and build a solid skill of English learning support system of professional. During the sophomore and junior students learned professional characteristic and student's interest in hobbies actual need. The practice mode set up in university professional compulsory EAP English courses, such as engineering English, business English, etc. Experience accumulation of the first two levels of learning, qualitative change layer focuses leap strength prior students' English learning ability, that is superb writing skills in English and fluent oral English ability. In this way, college English teaching can cultivate a solid English language skills and extensive professional knowledge.

\section{Establish New Mode of General English Teaching Based on EAP in Fujian-Taiwan Cooperation of Universities}

Teaching Mode. Under the specific Chinese higher education teaching context, the aim of students learning English is to use English directly engaged in their professional study or in English directly engaged in the future work, so that there in the relevant field has strong ability of international communication. Students use English situation mainly include listening to lectures, reports show, course thesis writing, discussions, individual learning, examination, and learning, including listening, speaking, reading and writing, so the teaching goal of EAP courses mainly includes the following three aspects: first, to enable students to master the basic skills of listening and speaking, can understand the main idea of different occasions, the use of English Center; second, improve students' discourse reading and writing ability; third, consolidate students' 
language knowledge. Under the guidance of the general teaching goal, respond to the specific teaching goal setting, such as EAP course in an oral presentation skill teaching objectives may include: effective use of communicative strategies, the proper use of body language, providing effective visual aids to attract the audience. From 2012, Fujian and Taiwan $3+1$ talent training mode firstly batched students. In 2015 July, students first to Taiwan exchange completed Taiwan a year study after switching back to Fuzhou University after just three years of time. In the face of the changes of social development and the situation, foreign language teaching should keep pace with the times to adapt to the requirements of the era of internationalization, individuation and specialization.

Teaching Materials. Due to the use of EAP courses, the material should be selected and the from the European and American mainstream newspaper articles, masters' works or celebrity lectures, reflecting the authentic language and the actual use of the language of English speaking countries. EAP teaching material is to meet the needs of students in the future to learn and work in English as a tool in the environment. Teaching materials to meet the students' needs, to reflect the students at present and in the future of language use, it is necessary to highlight the practical, selected students might encounter in the future study and work and be able to use the theme, genre and language. According to students for professional and language aspects of knowledge learning rules, from the teachers professional content understanding and acceptance of, English teachers and professional teachers can together to write a basic professional textbooks, this for English teachers professional knowledge background requirements is not very high, has feasibility. Academic English textbooks writing should not only pay attention to language. Interest, but also pay attention to knowledge and information, common knowledge of the subject and the language ability is the bilingual teaching in Colleges and universities of the starting point and the ultimate goal is the only standard to test the success of the bilingual teaching, academic English textbooks written also should take this as basis. The difference between Fujian and Taiwan University English education is also reflected in the selection of English textbooks. Although the use of English courses in College English courses in Fujian universities vary, but most of the well-known foreign language colleges and universities choose to publish a series of textbooks. In contrast, the use of English language courses in Taiwan colleges and universities, regardless of the type or from the source channels, are more abundant than the Fujian university. As the English education in Colleges and universities in Taiwan covers two parts of general English and academic English, therefore, there are many kinds of related courses offered by the school. Each teacher will choose the textbooks published by the local press according to the requirements of the course.

Teaching Form. The EAP courses are divided into two forms named centralized teaching form and decentralized teaching form. The centralized teaching form is refers to the student in learning other in English before the media the main academic curriculum learning EAP courses. The purpose is to let students familiar with the new environment, learn to take special learning methods and learning strategies and study skills, cultivate the consciousness of cross culture communication, for the future in English as the medium of course learn successfully hit the foundation; decentralized tutorial refer to students in learning other English medium main academic curriculum and learning EAP courses, a week out of a certain amount of time to carry out the necessary language training. The English education in Taiwan universities and colleges in Fujian are different. In order to conform to the trend of internationalization of education, attract more overseas students in Taiwan studying, English education in Universities in Taiwan in recent years occurred great change. The focus of English teaching has changed from the original English to the academic English which is based on the improvement of students' professional academic ability and in line with the needs of 
their future career planning. In the teaching practice, Taiwan universities have gradually formed a set of Special English teaching mode, which is mainly based on the academic English, and is a subsidiary of general English. In order to achieve the goal of college English teaching between Fujian and Taiwan must be drastic reform of the teaching mode. This model can provide students with the real world of stimulation and output opportunities effectively stimulate students' learning motivation, promote students' autonomous learning, communication, coordination and unity and cooperation. It can provide a lot of opportunities for the students to go abroad to study and conduct the academic exchange.

Teaching Assessment. The teaching assessments on English education between Fujian and Taiwan are similar. The personal presentation, group discussion, role playing and other forms make the English classroom teaching full of color. Multimedia and the Internet, as a new teaching aid, have been widely used in teaching practice by the English teachers in both places. However, there are still differences in English teaching between the two universities. Overall, compared with the universities in Taiwan, Fujian college classroom atmosphere is more relaxed, the form of teaching is also more random. Teachers and students break the inherent role of the relationship, in the context of more equal interaction. Curriculum evaluation is an objective reflection of students' learning situation and learning effect, and scientific, comprehensive and objective curriculum evaluation is an important guarantee to realize the goal of curriculum teaching. In the academic English teaching stage, the teaching material which is closely combined with the specialty is adopted, and the content is arranged by the shallow person deeply. This phase needs to strengthen the training of learning skills. In the process of teaching, teachers need to cooperate with the professional teachers to prepare lessons, or to take part of the teaching tasks. Academic English teaching stage requires students to master a certain amount of academic vocabulary and learning skills, to be able to successfully and critically read the academic literature, and have a certain level of English language communication skills. In general, EAP curriculum assessment is divided into two types of formative assessment and end assessment. The purpose of the EAP curriculum evaluation is to achieve the teaching objectives. Due to the students' dynamic needs, the course evaluation should also be flexible and diverse.

\section{Conclusion}

The development of the co-cultivation project between Fujian and Taiwan provided a good opportunity for the reform of English education in universities. As a pioneer and beneficiary, Fuzhou University cooperated with Taiwan universities and brought full play to their respective advantages of English education to explore the new mode of EAP. EAP will play a greater role in general English education in Fujian-Taiwan cooperation of universities.

\section{References}

[1] Que Shitao, Journal of Minjiang University, Vol. 25(2015) No 6, p.133-137

[2] Sun Yunbo, Feng Jie, Journal of Kunming University of Science and Technology (Social Science Edition), Vol. 14(2014) No 6, p.89-96

[3] Ding Linlin, Education Exploration, Vol. 23(2013) No 9, p.154-155

[4] Hu Pingyin, Education Review, Vol. 22(2016) No 3, p.73-76 
[5] Chen Jiao, Zhang Yuxuan, Li Lanjie, Theory Research, Vol. 58(2016) No 11, p.112-113 